\title{
"Lever Technique": A Novel Approach to Cope with Unstable Scope Position during Bottom-up Needle Knife Access (with Video)
}

\author{
Vincent Zimmere
}

\begin{abstract}
Needle knife papillotomy has become an invaluable advanced biliary access technique in routine endoscopic retrograde cholangiopancreatography (ERCP). Albeit poorly standardized in terms of procedural details, usually superficial cuts are applied to open the bile duct in an onion-like manner. However, this implies the capability to direct cuts from some distance from the papilla controlling needle knife movements in a complex fashion involving elevator movements. Here, an as-yet unreported technique designated the "lever technique" is presented for difficult needle knife access, when encountering technical difficulties, such as unstable scope position and awkward bile duct angle to allow for controlled needle knife navigation. In such variant rescue approach involving well-characterized prepapillary stone impaction by preceding same-session endoscopic ultrasound (EUS), thus providing some safety plane, ultranear-view instrumentation is coupled with exclusive needle knife navigation by moving the large dial, thus moving scope and needle knife-like as one endoscopic device.

Keywords: Biliary access, Biliary pancreatitis, Choledocholithiasis, Endoscopic ultrasound, Gall stone disease, Needle knife papillotomy, Scopic retrograde cholangiopancreatography.

Euroasian Journal of Hepato-Gastroenterology (2021): 10.5005/jp-journals-10018-1349
\end{abstract}

\section{Case Description}

A 24-year-old male patient with ulcerative colitis in remission on azathioprine presented at day 11 postuncomplicated laparoscopic cholecystectomy with acute upper abdominal pain radiating to the back. Laboratory assessment indicated elevated liver function tests (ALAT $539 \mathrm{U} / \mathrm{L}$ ) as well as minor increases in pancreatic enzymes (lipase $399 \mathrm{U} / \mathrm{L}$ ), suggestive of mild biliary pancreatitis. The patient underwent urgent same-session endoscopic ultrasound (EUS) and endoscopic retrograde cholangiopancreatography (ERCP) in a left lateral position. EUS indicated prepapillary impaction of an estimated 5-mm stone (Fig. 1A). After difficult biliary access on wire-guided cannulation due to a sharp bile duct axis and unstable scope position, we opted for early "bottom-up" needle knife access. However, simulation of cuts likewise indicated an awkward angle for controlled superficial incisions (Fig. 1B). In consideration of the impacted stone, providing a certain safety plane, we applied an as-yet unreported technique designated the "lever technique," involving ultranear-view instrumentation and directing cuts exclusively through moving the large dial, navigating scope and needle knife as one piece. This resulted in an immediate transmural opening of the common bile duct with a black pigment stone visualized (Fig. 1C; suppl. Video). The procedure was terminated without complications after wire-guided extensional papillotomy and subsequent stone extraction (Fig. 1D).

\section{Discussion}

EUS is an integral component in the non- or minimal-invasive diagnosis of biliary stone disease. ${ }^{1}$ Given the highly dynamic
Department of Medicine II, Saarland University Medical Center, Homburg, Deutschland, Germany

Corresponding Author: Vincent Zimmer, Department of Medicine II, Saarland University Medical Center, Homburg, Deutschland, Germany, Phone: +496841173755 , e-mail: vincent. zimmer@gmx.de

How to cite this article: Zimmer V. "Lever Technique": A Novel Approach to Cope with Unstable Scope Position during Bottom-up Needle Knife Access (with Video). Euroasian J Hepato-Gastroenterol 2021;11(2):95-96.

Source of support: Nil

Conflict of interest: None

nature of bile duct stones with a high propensity for spontaneous passage, same-session EUS-ERCP provides a unique real-time stratification of individual patients for invasive ERCP. ${ }^{2}$ Unless either duct is accessed during cannulation attempts, freehand needle knife papillotomy or fistulotomy remains the preferred rescue technique in day-to-day ERCP practice, however, with a low level of procedural standardization. Notwithstanding, EUS-guided individualized variations in needle knife techniques tailored to the specific anatomy present are achievable and may aid in procedural completion in otherwise challenging settings. ${ }^{3}$

\section{OrCID}

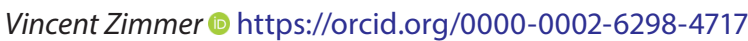

(-) The Author(s). 2021 Open Access This article is distributed under the terms of the Creative Commons Attribution 4.0 International License (https://creativecommons. org/licenses/by-nc/4.0/), which permits unrestricted use, distribution, and non-commercial reproduction in any medium, provided you give appropriate credit to the original author(s) and the source, provide a link to the Creative Commons license, and indicate if changes were made. The Creative Commons Public Domain Dedication waiver (http://creativecommons.org/publicdomain/zero/1.0/) applies to the data made available in this article, unless otherwise stated. 

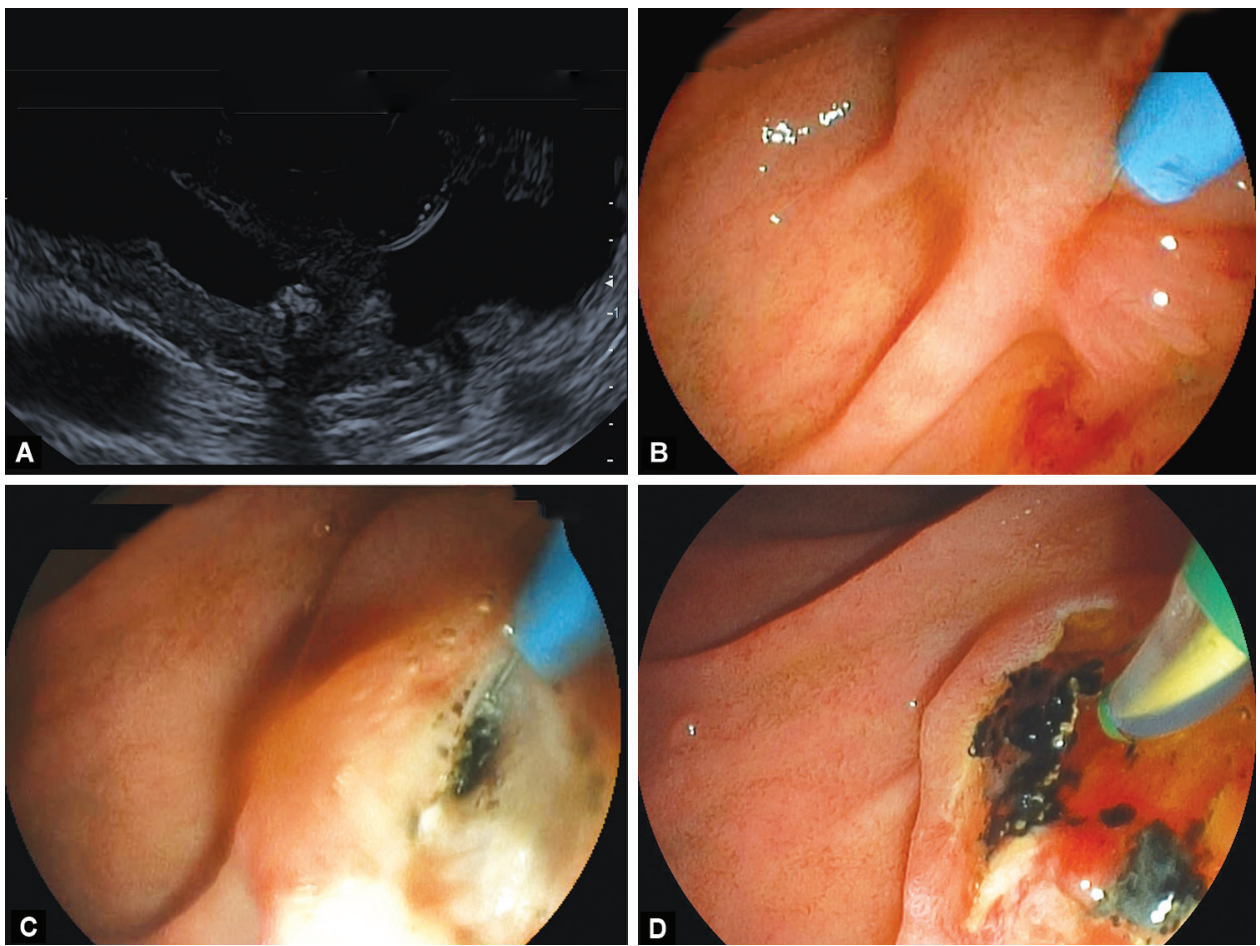

Figs 1 A to D: (A) Longitudinal EUS indicating an estimated 5-mm distal CBD stone with prepapillary impaction; (B) Conventional wire-guided biliary access during same-session EUS-ERCP failed due to sharp axis and unstable scope position; (C) Successful biliary access using the "lever technique" involving ultranear-view instrumentation with exclusive navigation with the large dial (compare also suppl. Video); (D) Stone extraction after conventional wire-guided access and extensional papillotomy

\section{References}

1. Beyna T, Gerges C. Clinical management of bile duct diseases: role of endoscopic ultrasound in a personalized approach. J Pers Med 2020;11(1):1. DOI: 10.3390/jpm11010001.

2. Moutinho-Ribeiro P, Peixoto A, Macedo G. Endoscopic retrograde cholangiopancreatography and endoscopic ultrasound: to be one traveler in converging roads. GE Port J Gastroenterol 2018;25(3): 138-145. DOI: 10.1159/000481537.

3. Testoni PA, Mariani A, Aabakken L, et al. Papillary cannulation and sphincterotomy techniques at ERCP: European Society of Gastrointestinal Endoscopy (ESGE) clinical guideline. Endoscopy 2016;48(7):657-683. DOI: 10.1055/s-0042-108641. 